\title{
Limitations of Information About Health Effects of Chemicals
}

$\mathbf{F}^{\circ}$ or two decades, the Occupational Safety and Health Administration (OSHA) has required manufacturers of chemicals to label their products and prepare material safety data sheets (MSDSs) so that workers who handle these materials can use them safely. This Hazard Communication Standard (29 CFR 1910.1200), known also as the "Right to Know," has been perhaps the most powerful legal tool available to workers and health care providers who need to identify chemicals that are in the workplace and learn how to use them safely. In addition to requiring MSDSs, the Hazard Communication Standard also requires the proper labeling of containers and piping, as well as training of workers or how to use these materials safely.

The cornerstone of the Hazard Communication Standard is the MSDS. From the vantage point of the health care provider, the MSDS provides one critical piece of information in assessing the relation between exposures and health - the identity of the chemical. However, three constraints limit the value of the MSDS to health care providers. First, the MSDS often does not contain the kind of information that would be of greatest value to the health care provider, such as chronic health effects data. Second, physicians often are ill-equipped to either critically evaluate or make good use of the information provided in the MSDS because they receive little or no training in occupational and environmental medicine, toxicology, and how to take an occupational and environmental history. Finally, MSDSs have no information about the magnitude of the chemical exposures in the workplace, so a critical piece of the puzzle, the estimated dose, is always missing.

In this issue, Frazier et al. consider this first constraint in evaluating the quality of health information contained in a number of MSDSs for toluene diisocyanate. ${ }^{1}$ Not surprisingly, they find great inconsistency in the quantity and quality of information on a well-described health effect, asthma due to toluene diisocyanate exposure. Of 30 MSDSs studied, only half mentioned asthma as a specific health concern, and only a quarter discussed the need to exclude workers who develop respiratory problems from further exposures. Obviously, a physician relying on the MSDS alone runs a substantial risk of having incomplete information about potential health effects.

Frazier et al. offer several useful suggestions about how to make MSDSs more accurate and useful to workers and physicians. These include more straightforward language, periodic review, a bibliography, and assistance from health professionals in the preparation of the MSDSs. However, it would be a mistake to think that even with these improvements, MSDSs could ever be completely accurate and reliable. There is an intrinsic bias to MSDSs, which are prepared by chemical manufacturers who will invariably require a high burden of proof to list an adverse health effect on the MSDS. They also must rely on incomplete information because of the lack of systematic testing of the health hazards of chemicals. Asthma is a well-accepted consequence of toluene diisocyanate exposure, yet Frazier et al. have shown that there are substantial inconsistencies in MSDSs. Physicians should be even more skeptical about the absence of other chronic and/or controversial health effects in MSDSs, such as reproductive or neurologic outcomes, which are not routinely evaluated in animal toxicologic studies, or cancer, which even well-intentioned manufacturers might omit without a high degree of scientific consensus.

The second constraint may be even more significant than the limitations of MSDSs themselves. The physician who is most frequently asked about the health effect of a chemical exposure at work or at home is an internist or other primary care provider. Most providers of occupational health services in the United States are physicians who are not residency trained in occupational and environmental medicine. Indeed, only $20 \%$ of the members of the American College of Occupational and Environmental Medicine have been certified by the American Board of Preventive Medicine. ${ }^{2}$ Unfortunately, most medical students and residents still receive little or no training in occupational and environmental medicine, despite years of attempts to modify medical curricula. $^{3-6}$

While physicians not aware of the aforementioned issues may be tempted to rely on the MSDS for health effects information, Frazier et al. have convincingly demonstrated the limitations of that approach. The MSDS is most useful as a starting point for the investigation of potential chemical exposures. Many if not most physicians now have access to online resources, including the National Library of Medicine's MEDLINE. A simple literature search on MEDLINE, using the words "toluene diisocyanate" and "asthma" with no other descriptors in all years, yields 261 references. Physicians can also use the ToxLINE database, which contains more references from the toxicological literature.

So what is the nonspecialist to do when the patient asks, "Is my work (or my home) making me sick?" Ideally, the physician will have some knowledge of occupational and environmental medicine and know how to approach issues of exposure assessment, toxicology, and risk assessment. Some patients will come armed with internet references (of varying accuracy) on the toxic effects of their exposures to certain chemicals. Medical generalists, who are on the front lines in evaluation of workers as patients, should be aware of the strengths and limitations of MSDSs, as well as the numerous resources available to assist both the patient and the practitioner. Valuable sources of information include government agencies, 
clinical organizations and professional societies: the National Institute for Occupational Safety and Health, http://www.cdc.gov/niosh/homepage.html; Occupational Safety and Health Administration, http:// www.osha.gov/; Environmental Protection Agency, http://www.epa.gov/; Agency for Toxic Substances and Disease Registry, http://www.atsdr.cdc.gov/; National Institute for Environmental Health Sciences, http:// www.niehs.nih.gov/; the Association of Occupational and Environmental Clinics, www.aoec.org; and the American College of Occupational and Environmental Medicine, http://www.acoem.org/. Clearly it is important to ask patients about workplace and home exposures, and recognize when additional information is required.

Like the rest of medicine, occupational and environmental medicine has seen an explosion of information resources available to both physicians and patients. Understanding the value - and the limitations - of that information will help both the patient and the physician make good choices about the prevention and treatment of work-related illness.-Clifford S. Mitchell, MS, MD, MPH, and BRIAN S. SchwarTZ, MD, MS, Department of
Environmental Health Sciences, Johns Hopkins University School of Hygiene and Public Health, Baltimore, Md.

\section{REFERENCES}

1. Frazier LM, Beasley BW, Sharma GK, Mohyuddin AA. Health information in material safety data sheets for a chemical that causes asthma. J Gen Intern Med. 2001;16:89-93.

2. Committee to Assess Training Needs for Occupational Safety and Health Personnel in the United States, Institute of Medicine. Safe Work in the 21st Century. Washington, DC: National Academy Press 2000;32-89.

3. Frazier LM, Cromer JW, Andolsek KM, Greenberg GN, Thomann WR, Stopford W. Teaching occupational and environmental medicine in primary care residency training programs: experience using three approaches during 1984-1991. Am J Med Sci. 1991; 302:42-5.

4. Cullen MR, Figuero ST. Incorporating environmental medicine into training programs in occupational medicine. J Occup Med. 1990;32:1104-07.

5. Burstein JM, Levy BS. The teaching of occupational health in US medical schools: little improvement in 9 years. Am J Public Health. 1994;84:846-9.

6. Cullen MR, Rosenstock L. The challenge of teaching occupational and environmental medicine in internal medicine residencies. Arch Intern Med. 1988;148:2401-4. 